\title{
Changes in the fecal concentrations of cortisol and androgen metabolites in captive male jaguars (Panthera onca) in response to stress
}

R.G. Morato ${ }^{1}$,

M.G. Bueno' ${ }^{2}$

P. Malmheister ${ }^{2}$,

I.T.N. Verreschi ${ }^{3}$ and R.C. Barnabe ${ }^{2}$

\author{
${ }^{1}$ Centro Nacional de Pesquisa para a Conservação dos Predadores Naturais \\ (CENAP-IBAMA), Associação Pró-Carnívoros, Faculdade de Medicina Veterinária, \\ Universidade Bandeirantes, São Bernardo do Campo, SP, Brasil \\ ${ }^{2}$ Departamento de Reprodução Animal, Faculdade de Medicina Veterinária e \\ Zootecnia, Universidade de São Paulo, São Paulo, SP, Brasil \\ ${ }^{3}$ Laboratório de Endocrinologia, Faculdade de Medicina, Universidade Federal de \\ São Paulo, São Paulo, SP, Brasil
}

\footnotetext{
Correspondence

R.G. Morato

Rua Dona Carmela, 55

12946-390 Atibaia, SP

Brasil

Fax: +55-11-4411-6966

E-mail: ronaldo@procarnivoros.org.br

Research supported by FAPESP

(No. 00/01044-1).
}

.....................

Received January 10, 2004 Accepted August 10, 2004 ....................

\begin{abstract}
In the present study we determined the efficacy of the measurement of fecal cortisol and androgen metabolite concentrations to monitor adrenal and testicular activity in the jaguar (Panthera onca). Three captive male jaguars were chemically restrained and electroejaculated once or twice within a period of two months. Fecal samples were collected daily for 5 days before and 5 days after the procedure and stored at $-20^{\circ} \mathrm{C}$ until extraction. Variations in the concentrations of cortisol and androgen metabolites before and after the procedure were determined by solid phase cortisol and testosterone radioimmunoassay and feces dry weight was determined by drying at $37^{\circ} \mathrm{C}$ for $24 \mathrm{~h}$ under vacuum. On four occasions, fecal cortisol metabolite levels were elevated above baseline $(307.8 \pm 17.5 \mathrm{ng} / \mathrm{g}$ dry feces $)$ in the first fecal sample collected after the procedure (100 to $350 \%$ above baseline). On one occasion, we did not detect any variation. Mean ( \pm SEM) fecal androgen concentration did not change after chemical restraint and electroejaculation (before: $131.1 \pm 26.7$, after: $213.7 \pm 43.6 \mathrm{ng} / \mathrm{g}$ dry feces). These data show that determination of fecal cortisol and androgen metabolites can be very useful for a noninvasive assessment of animal well-being and as a complement to behavioral, physiological, and pathological studies. It can also be useful for the study of the relationship between adrenal activity and reproductive performance in the jaguar.
\end{abstract}

The reproductive function of mammals is reduced by stress, and a variety of mediating factors have been suggested, including cortisol (1-4). Hormones secreted during stress are also capable of reducing testosterone concentrations in males $(1,5,6)$.
Key words

- Fecal cortisol metabolite

- Fecal androgen metabolite

- Jaguar (Pantera onca)

- Captivity

- Chemical restraint

- Electroejaculation
For many species, including felids, failure to reproduce in captivity has been attributed to stress ensuing from sub-optimal housing and husbandry conditions $(7,8)$. In the management of such animals it is important to determine if housing conditions, handling, 
anesthesia, or electroejaculation acutely or chronically influence reproductive function or general physiological status (9). Since it is accepted that stressful stimuli can induce ACTH release, which increases the synthesis and secretion of cortisol by the adrenal glands (10), cortisol analysis has been widely used as an index of stress (11-13). Thus, chronic stress has been demonstrated by elevated blood cortisol levels in mammal species $(3,4,14,15)$. Recently, Graham and Brown (12) demonstrated that adrenocortical activity can be monitored noninvasively in the cat by measuring cortisol metabolites excreted in the feces, a useful procedure for evaluating responses to physiological and psychological stressors associated with environmental conditions and husbandry practices.

Therefore, the objectives of the present study were: 1) to determine if fecal cortisol analysis would be an appropriate technique for monitoring adrenal activity in the jaguar, and 2) to investigate changes in cortisol and androgen metabolite concentrations after chemical restraint and electroejaculation in the jaguar.

Male jaguars were maintained in individual cages at the Ilha Solteira Zoo $(\mathrm{N}=1$; P01), and housed with females at the Rio de Janeiro Zoo $(\mathrm{N}=2$; P02, P03). Mean ( \pm SD) age based on known dates of birth $(\mathrm{N}=1)$ and dentition and tooth wear $(\mathrm{N}=2)$ was $72.0 \pm 24.0$ months. All animals were fed a meat-based diet (beef with occasional bones, but without vitamin or mineral supplementation, or organ meat), and had free access to water. Procedures were in accordance with the Internal Committees of Ilha Solteira and Rio Zoo.

Jaguars were anesthetized with a combination of tiletamine and zolazepam $(10 \mathrm{mg} /$ kg; Zoletil 50; Virbac do Brasil, São Paulo, SP, Brazil) administered using a blow dart system. Electroejaculation was performed as previously described by Morato et al. (16). Briefly, a rectal probe $(2.6 \mathrm{~cm}$ in diam- eter and $29 \mathrm{~cm}$ long) and a portable batteryoperated electrostimulator (AC, $60 \mathrm{~Hz}$ current; Eletrovet Electronic Equipment, São Paulo, SP, Brazil) were used to deliver an electroejaculation stimulus sequence consisting of a total of 80 stimuli applied in a series of 30, 30 and 20 stimuli. Three series were applied with 10-min intervals between series. Animals P01 and P03 were submitted to chemical restraint and electroejaculation twice with a 2-month interval between procedures, and animal P02 was submitted to the same procedure only once.

To evaluate the influence of chemical restraint and electroejaculation on cortisol and testosterone metabolite concentrations, fecal samples from each animal were collected daily for 5 days before and 5 days after the procedure. Samples were frozen $\left(-20^{\circ} \mathrm{C}\right)$ and stored until the extraction procedure.

Extraction was performed as described by Graham and Brown (12). Briefly, samples were dried with a Speedvac Evaporator System $\left(37^{\circ} \mathrm{C} / 24 \mathrm{~h}\right.$; Forma Scientific Inc., Marietta, OH, USA), pulverized, and $0.2 \mathrm{~g}$ was boiled in $5 \mathrm{ml}$ of $90 \%$ ethanol:distilled water $(\mathrm{v} / \mathrm{v})$ for $20 \mathrm{~min}$. After centrifugation at $500 \mathrm{~g}$ for $20 \mathrm{~min}$, the supernatants were recovered and the pellets resuspended in an additional 5-ml portion of $90 \%$ ethanol, vortexed, and centrifuged again. The combined supernatants were evaporated dry under air, resuspended in $1 \mathrm{ml}$ methanol, and then further diluted (1:2) in gelatin buffer (60 $\mathrm{mM}$ sodium phosphate, $\mathrm{pH} 7.0,0.4 \mathrm{M} \mathrm{NaCl}$, and $10 \%$ gelatin, w/v) for radioimmunoassay (RIA). The extraction procedure was validated by demonstrating a significant recovery of the exogenous $\left[{ }^{3} \mathrm{H}\right]$-cortisol and $\left[{ }^{3} \mathrm{H}\right]$-testosterone added to each fecal sample (cortisol (mean \pm SEM): $78.0 \pm 0.8 \%$ and testosterone: $83.0 \pm 1.0 \%$ ). All analyses were performed in duplicate.

A solid-phase ${ }^{125}$ I RIA for cortisol and testosterone (Diagnostic Products Corporation, Los Angeles, CA, USA) was used to quantify the immunoactive fecal corticoid 
and androgen concentrations. The assay was validated for the jaguar by demonstrating parallelism between dilutions of pooled extracts and the standard curve (cortisol: $\mathrm{y}=$ $1.6-1.1 \mathrm{x}, \mathrm{r}^{2}=0.99$, and testosterone: $\mathrm{y}=1.3$ $0.92 x, r^{2}=0.99$; Spearman). Assay sensitivity based on $91 \%$ of maximum binding was $12.5 \mathrm{ng} / \mathrm{ml}$ per tube for cortisol and 8 pg per tube for testosterone. Intra- and inter-assay coefficients of variation were $<10 \%$. Data are reported on a per $\mathrm{g}$ fecal dry weight basis.

For each jaguar, the mean baseline concentration for cortisol metabolites was designated as $100 \%$, and pre- and post-chemical restraint and electroejaculation values are presented as a percentage of baseline. Increases in cortisol metabolite excretion were considered to be significant if they exceeded the baseline mean plus 2 SD. Differences between pre- and post-electroejaculation mean values of fecal androgen metabolites were compared using the Mann-Whitney rank test. The Spearman correlation test was applied to verify the relationship between fecal cortisol metabolites and fecal androgen metabolites.

Serum cortisol has been extensively used as a stress indicator in many mammalian species $(3,4,14,15)$. Recently, fecal cortisol metabolites have been identified as an index of stress in zoo animals $(12,17,18)$. Since many captive and wild populations of endangered species such as the jaguar are intensively managed, measuring fecal cortisol metabolites will be useful to identify factors affecting animal well-being in captivity. In addition, adrenal activity could be measured in wild jaguars by closely monitoring radiocollared animals to collect a fresh sample or by obtaining fecal samples during capture for radio-collaring.

Animals have been exposed to chemical restraint or electroejaculation to assess the ability of fecal corticoid metabolite analysis to detect changes in adrenocortical activity (17). In the present study, using five chemical restraint and electroejaculation proce- dures we were able to detect changes in the cortisol metabolite concentrations on four occasions (Figure 1). Increased concentrations normally occurred on the first day after chemical restraint and electroejaculation. Increases in fecal corticoid excretion in domestic cats were typically observed in the first fecal sample collected as early as $24 \mathrm{~h}$ after an ACTH challenge (17). Similarly,

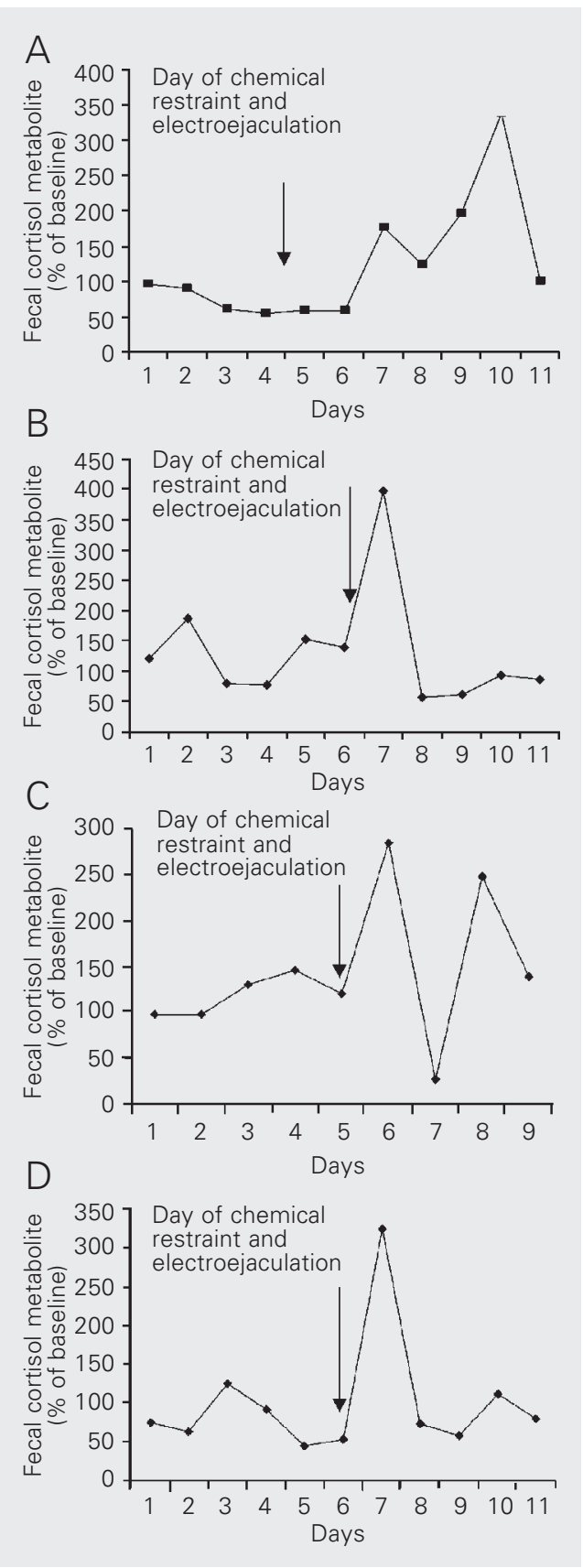

Figure 1. Response of fecal cortisol metabolite to electroejaculation and chemical restraint in the jaguar (Panthera onca). Data are reported as mean percent per day for individual animals compared to baseline values, which were the average value for 5 days before the procedure. $A$, First procedure for animal P01; baseline value: $232.4 \pm$ $27.6 \mathrm{ng} / \mathrm{g}$ dry feces. $B$, Second procedure for animal P01; baseline value: $399.7 \pm 68.8 \mathrm{ng} / \mathrm{g}$ dry feces. $C$, First procedure for animal P02; baseline value: 380.0 $\pm 38.7 \mathrm{ng} / \mathrm{g}$ dry feces. $D$, Second procedure for animal P03; baseline value: $259.9 \pm 43.9 \mathrm{ng} /$ $g$ dry feces. 
peaks of fecal cortisol excretion were observed in the first fecal sample collection from three of four cheetahs (Acinonyx jubatus). However, in one of these animals, the peak of fecal corticoid excretion was observed $72 \mathrm{~h}$ post-immobilization (17). Since on one occasion we were unable to collect fecal samples after the first day postchemical restraint and electroejaculation, it is possible that changes occurred after the first collection.

In the present study, mean fecal cortisol metabolites increased 2- to 4-fold over the pre-chemical restraint and electroejaculation levels, while they increased 6- to 12-fold over the pre-ACTH challenge and 2- to 9fold after immobilization in the cheetah (17). In general, cortisol metabolism appears to be conserved among felid species (17). Since cat species produce cortisol and corticosterone, it is possible that the difference among studies is related to the use of different RIA in each. In the present study, fecal cortisol metabolite concentrations ranged from 4.0 to $1276.6 \mathrm{ng} / \mathrm{g}$ dry feces. Mean overall fecal cortisol metabolite concentration was 418.0 $\pm 35.0 \mathrm{ng} / \mathrm{g}$ dry feces, mean baseline concentration was $307.8 \pm 17.5 \mathrm{ng} / \mathrm{g}$ dry feces, and mean peak concentration was $820.9 \pm 86.8$ $\mathrm{ng} / \mathrm{g}$ dry feces. Similar ranges were reported for clouded leopards (Neofelis nebulosa) (18), although the mean overall, baseline and peak concentrations described here were 3- to 4-fold higher than those described for the clouded leopard (18) and cheetah (19).

Glucocorticoids appear to act on the pituitary and testes to suppress testosterone (20) and an elevation of glucocorticoids in serum precedes the decline of the serum testosterone concentration in the wild baboon (1). However, cortisol release in immobilized and electroejaculated cheetahs did not appear to affect the tonic release of testoster- one or luteinizing hormone (9). Similarly, in this study, we did not find a variation in fecal androgen concentrations between the time before and after chemical restraint and electroejaculation $(131.1 \pm 26.7$ vs $213.7 \pm 43.6$ $\mathrm{ng} / \mathrm{g}$ dry feces). In addition, there was no correlation $(\mathrm{P}>0.05)$ between fecal cortisol metabolites and fecal androgen metabolites. Consequently, there is no evidence that chemical restraint and electroejaculation-induced cortisol secretion exert a modulating influence on testosterone.

The present study shows that determination of fecal cortisol and androgen metabolites can be very useful for noninvasively assessing an animal's well-being and for complementing behavioral, physiologic, and pathologic studies. However, the relationship between adrenal activity and reproductive performance still remains to be investigated in the jaguar. At the conservation strategy level, this technique is clearly useful to assess whether housing conditions, handling or other manipulatory procedures can affect the reproductive and/or general physiological status of captive animals. In addition, it is possible to use these techniques to evaluate changes in the reproductive and/or physiological status of free-living populations in the presence of the pressures due to human intervention.

\section{Acknowledgments}

The authors would like to thank the staff of Fundação Rio-Zoo and Parque Zoológico de Ilha Solteira for assistance with sample collection. We are also grateful to Priscila Viau (DVM, MSc.) and Prof. Dr. Claudio Alvarenga de Oliveira for help with the laboratory procedures. Finally, we would like to thank two anonymous reviewers for helpful comments and suggestions. 


\section{References}

1. Sapolsky RM (1985). Stress-induced suppression of testicular function in the wild baboon: role of glucocorticoids. Endocrinology, 116: 2273-2278.

2. Moberg GP (1985). Influence of stress on reproduction: a measure of well-being. In: Moberg GP (Editor), Animal Stress. American Physiological Society, Bethesda, MD, USA, 27-50.

3. Von Hoslt D (1998). The concept of stress and its relevance for animal behavior. In: Moller AP, Milinski M \& Slater PJB (Editors), Stress and Behavior. Academic Press, London, UK, 1-132.

4. Jasnow AM, Drazen DL, Huhman KL, Nelson RJ \& Demas GE (2001). Acute and chronic social defeat suppresses humoral immunity of male Syrian hamsters (Mesocricetus auratus). Hormones and Behavior, 40: 428-433.

5. Bambino TH \& Hsueh JW (1981). Direct inhibitory effect of glucocorticoids upon testicular luteinizing hormone receptor and steroidogenesis in vivo and in vitro. Endocrinology, 108: 2142-2148.

6. Cumming DC, Quigley ME \& Yen SS (1983). Acute suppression of circulating testosterone levels by cortisol in men. Journal of Clinical Endocrinology and Metabolism, 57: 671-673.

7. Moberg GP (1987). Problems in defining stress and distress in animals. Journal of the American Veterinary Medical Association, 191: 1207-1211.

8. Mellen JD (1991). Factors influencing reproductive success in small captive exotic felids (Felis ssp.): a multiple regression analysis. Zoo Biology, 10: 95-110.

9. Wildt DE, Meltzer D, Chacraborty PK \& Bush M (1984). Adrenaltesticular-pituitary relationships in the cheetah subjected to anesthesia/electroejaculation. Biology of Reproduction, 30: 665-672.

10. Jones MT (1979). Control of adrenocortical hormone secretion. In: James VHT (Editors), The Adrenal Gland. Raven Press, New York, 93-103.

11. Jessup DA (1993). Remote treatment and monitoring of wildlife. In: Fowler ME (Editor), Zoo and Wild Animal Medicine and Current Therapy. WB Saunders Company, Philadelphia, PA, USA, 499-504.
12. Graham LH \& Brown JL (1996). Cortisol metabolism in the domestic cat and implications for non-invasive monitoring of adrenocortical function in endangered felids. Zoo Biology, 15: 71-82.

13. Hierbert SM, Ramenofsky M, Salvante K, Wingfield JC \& Gass CL (2000). Noninvasive methods for measuring and manipulating costicosterone in hummingbirds. General and Comparative Endocrinology, 120: 235-247.

14. Fraser AF \& Broom DM (1990). Farm Animal Behaviour and Welfare. Baillière Tindall, Paris, France.

15. Mendoza SP (1991). Behavioural and physiological indices of social relationships: comparative studies of New World monkeys. In: Box $\mathrm{HO}$ (Editor), Primate Responses to Environmental Change. Chapman \& Hall, London, UK, 311-335.

16. Morato RG, Conforti VA, Azevedo FC, Jacomo ATA, Silveira L, Sana D, Nunes ALV, Guimarães MABV \& Barnabé RC (2001). Comparative analyses of semen and endocrine characteristics of free-living versus captive jaguars (Panthera onca). Reproduction, 122: 745751.

17. Terio KS, Citino SB \& Brown JL (1999). Fecal cortisol metabolite analysis for non-invasive monitoring of adrenocortical function in the cheetah (Acinonyx jubatus). Journal of Zoo and Wildlife Medicine, 30: 484-491

18. Wielebnowski NC, Fletchall N, Carlstead K, Busso JM \& Brown JL (2002). Non-invasive assessment of adrenal activity associated with husbandry and behavior factors in the North American clouded leopard population. Zoo Biology, 21: 77-98.

19. Wielebnowski NC, Ziegler K, Wildt DE, Lukas J \& Brown JL (2002). Impact of social management on reproductive, adrenal and behavioural activity in the cheetah (Acinonyx jubatus). Animal Conservation, 5: 291-301.

20. Chantaraprateep $P$ \& Thibier M (1978). Effects of dexamethasone on the response of luteinizing hormone and testosterone to two injections of luteinizing hormone releasing hormone in young post pubertal bulls. Journal of Endocrinology, 77: 389-395. 